\title{
Assessment of the effect of vegetation on the transition of the flood wave using hydraulic 2D models
}

\author{
Krzysztof Wolski ${ }^{1,{ }^{*}}$, Tomasz Tyminski ${ }^{1}$, and Pawel B. Dabek ${ }^{2}$ \\ ${ }^{1}$ Wroclaw University of Environmental and Life Sciences, The Faculty of Environmental Engineering \\ and Geodesy, Institute of Environmental Engineering, C. K. Norwida 25, 50-375 Wroclaw, Poland \\ ${ }^{2}$ Wroclaw University of Environmental and Life Sciences, The Faculty of Environmental Engineering \\ and Geodesy, Institute of Environmental Protection and Development, C. K. Norwida 25, 50-375 \\ Wroclaw, Poland
}

\begin{abstract}
In the paper an impact of vegetation accumulation on flood wave transition is presented. The research was conducted with use of the MIKE FLOOD model which combines elements of 1D and 2D numerical models. The study area included a $5.5 \mathrm{~km}$ long section of the Bystrzyca River near Wroclaw, Poland. A hydraulic model was constructed, on which the simulation of water transition with the probability of occurrence $p=1 \%$ and $p=0.2 \%$ was conducted. The simulation was carried out for current bank vegetation conditions determined on the basis of precise LIDAR data and for conditions with no vegetation. In this way, the direct impact of vegetation on flood wave transition was obtained. Acquired results, a decrease in maximum water levels and a reduction of flooded area, show that the hydraulic influence of vegetation on high water bed should not be underestimated.
\end{abstract}

\section{Introduction}

The outbreak of water from river bed is a natural process which accompanied humanity for ages. It were the river valleys where first human settlements arose which could develop agriculture thanks to the river flooding providing fertile sediments. Aside from beneficial effect, floods were also causing damage and death of many people. Nowadays floods are considered hazardous phenomena and humanity, at all costs, is trying to prevent them with use of active and passive measures of flood protection. It is well known that in recent years the number of floods and loss associated with them is growing [1,2], which is caused by changes in land use patterns, climate, and also changes in land management in river valleys $[3,4]$. Among important issues connected with river management, the understanding of flood events and predicting flood-prone areas and potential damage have become especially compelling [2].

Flood prediction with use of numerical simulations is a crucial element of flood protection management. With use of such predictions, recommendations can be proposed concerning

\footnotetext{
* Corresponding author: krzysztof.wolski@upwr.edu.pl
} 
adequate means of prevention on appointed flood-prone areas [5, 6]. A basic set of input data for hydrodynamic models includes geometry, information on roughness and boundary conditions (e.g. flows and water level) [7].

For flood flows the roughness of flood-prone valley has a significant impact. Banks of the main channel and floodplain have their slopes covered with vegetation, which can take the form of diverse grasses, perennials, reeds, sedges, shrubs and trees [8]. Proper hydrodynamic-numerical modelling should have roughness parameterized by a friction coefficient that is an empirical value [7], such as Manning's $n$ [9] or Chezy's $C$ [10]. Manning's $n$ values have been featured in a great deal of literature $[9,11,12]$ and, although they present a good reference, caution is necessary while picking up the values as they are quite general [13]. Little effort has been made, despite of the above findings, to update Manning's $n$ as the parameter is continuously changed and calibrated [14]. Nevertheless, the roughness value loses its relevance during this process and it is valuable engineering to have Manning's $n$ more precisely estimated at the first time to reduce calibration and provide improved definition [13].

The difficulties in the description of vegetal zones roughness result largely from its variability in time and space. The spatial variability results from the distribution of plants in clusters and then clusters in floodplain, variable density and shape of vegetation, but also diversity of species, where different kinds of vegetation have distinctive hydromorphologic features that impact the flow resistance. When it comes to time, the variability in roughness results, on the one hand, from seasonal diversification mainly in vegetation phases, foliation and humidity of plants, which can translate on each flexibility of plants and other ways of buckling during the transition of flood wave, and, on the other hand, from diversity during the flood stage, where at diverse depth of water, and in an indirect manner by flow intensity, various plants "act" differently, resulting in totally different resistance. For that reason, despite numerous experimental research, to this day there were no efficient methods constructed concerning automatic development of roughness coefficient for use in large hydrodynamic models which simulate flow in the case of big rivers.

The data sources for the spatial distribution of roughness coefficient could be the CORINE LAND COVER database, BDOT base, ortophotos, digital elevation models (DEM), ALS data and satellite data. Current trends suggest that roughness data should be acquired with use of various mixed remote-sensing data. It can lead to the occurrence of an efficient way for the estimation of vegetal roughness for the purpose of hydraulic practice, because it is more feasible than the execution of complex field research or laboratory experiments [2, 10, 13, 15-18].

The issue of vegetal damming evaluation was discussed by, among others, Tyminski [19] with use of analytic methods of Rickert and Manning. He proved, on the 291.300 crosssections of the Odra River near Slup, that during the 1997 water rising the vegetation impact caused an increase of water level of approximately half a meter. This research became an inspiration for this paper.

\section{Study area}

The research was conducted for the outlet area of the Bystrzyca River from 5.127 to 10.650 kilometres. The modelled section of the Bystrzyca River is located in the range of geographical location $16^{\circ} 51^{\prime} 40^{\prime \prime}$ and $16^{\circ} 53^{\prime} 40^{\prime \prime}$ East longitude, and $51^{\circ} 7^{\prime} 30^{\prime \prime}$ and $52^{\circ} 0^{\prime} 00^{\prime \prime}$ North latitude. The Bystrzyca River is a left-bank tributary of the Odra River. Its length is about $101.5 \mathrm{~km}$, and the catchment area equals ca. $1768 \mathrm{~km}^{2}$. The location of the surveyed segment of the river is presented in Fig. 1. During the analysis the final segment of the Bystrzyca River was selected, but its distance from the estuary was purposely estimated in order to avoid an impact on its floodplain caused by the backwater from the Odra River. The 
floodplain consists of varied composition of trees, bushes and surfaces of low vegetation (grasslands, wastelands). In the potential flood zone there are also buildings located. In terms of the terrain layout the river valley with a mean width from 150 to 600 metres is a drop of terrain (height from 112-114 m a.s.l. Kronstadt), in which the outcome of high waters is possible.
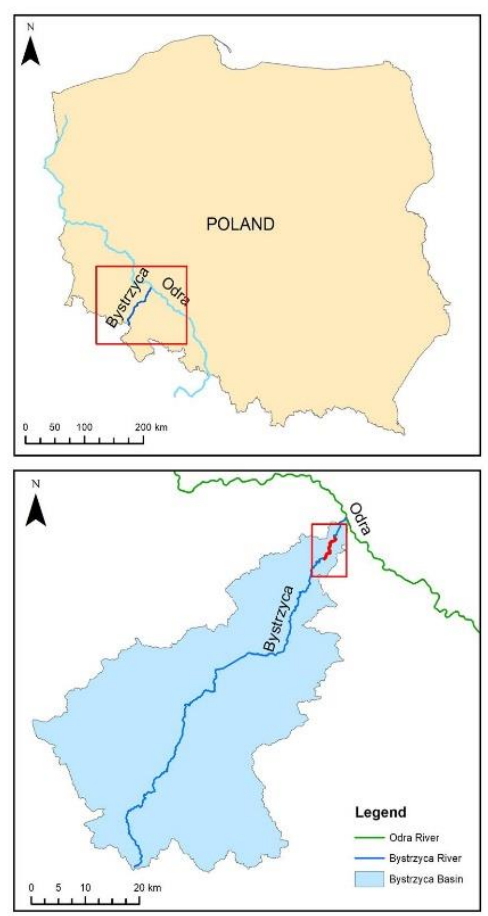

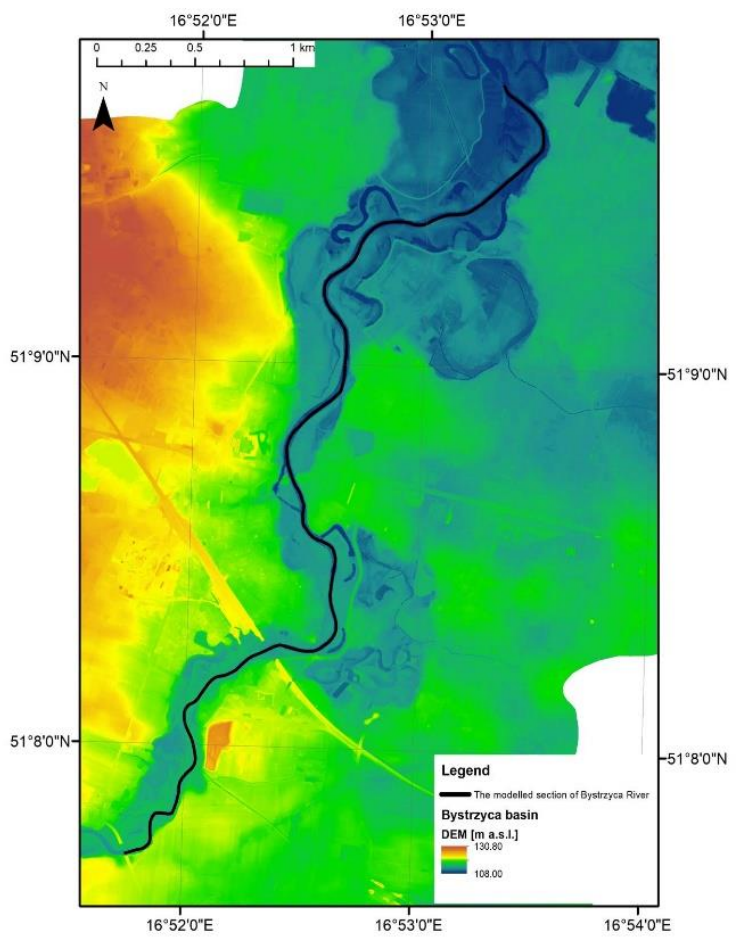

Fig. 1. Area of study - modelled section of the Bystrzyca River against DEM (right), and in reference to Poland (top left) and the Bystrzyca basin (bottom left).

\section{Methods}

\subsection{Hydraulic assumptions}

At the reach scale, flow resistance is defined in all classical flow formulas in open channels using different coefficients $(C, n, \lambda)$. In Table 1 we showed Equations $1-3$. Standard hydraulic texts or formulas are not described but briefly cited as appropriate, since there are excellent review papers available [e.g. 20,21].

Table 1. Classical flow formulas in open channel (where: $v$ - mean flow velocity $\left[\mathrm{ms}^{-1}\right]$, $C, n, \lambda$-resistance coefficients (respectively Chezy's, Manning's and Darcy-Weisbach's), $R_{h}$-hydraulic radius [m], $I$ - bottom or energy slope for uniform and non-uniform flows, respectively [-], $g$ - gravitational acceleration $\left.\left[\mathrm{ms}^{-2}\right]\right)$.

\begin{tabular}{|c|c|}
\hline Authors & Formulas \\
\hline Chezy formula & $v=C \cdot\left(R_{h} \cdot I\right)^{(1 / 2)}$ \\
\hline Darcy-Weisbach formula & $v=\lambda^{(-1 / 2)} \cdot\left(8 \cdot g \cdot R_{h} \cdot I\right)^{(1 / 2)}$ \\
\hline Manning formula & $v=n^{(-1)} \cdot R_{h}^{(2 / 3)} \cdot I^{(1 / 2)}$ \\
\hline
\end{tabular}


All resistance coefficients are related according to the formula in Equation 4 [22]:

$$
C=\sqrt{\frac{8 g}{\lambda}}=\frac{1}{n} R_{h}^{(1 / 6)}
$$

These coefficients include all resistance in the trough, but most researchers have stated that the role of vegetation in channel is crucial [23, 24]. In engineering practice, in order to meet the requirements of hydraulic modeling, tables containing the resistance coefficients for channel and river valley covering are used $[9,11]$. Most frequently Manning's $n$ coefficient is used in MIKE models. Therefore in this paper it was adapted to specify the roughness as well.

\subsection{Hydrodynamic model}

Hydrodynamic simulation was performed in MIKE FLOOD software, which connects the features of 1D and 2D models. The 1D model is prepared within the component of the MIKE 11 model. It encompasses the area of main river bed described with use of transverse crosssections deployed in specified distances. The floodplain on the banks is modelled with use of the 2D model (MIKE 21 component) where the whole area is described with GRID net, in which the area bathymetry is spatially distributed and the roughness is represented by Manning's coefficient. The MIKE 11 and MIKE 21 models were then coupled using lateral links to form the MIKE FLOOD model. The MIKE software is on the hydraulic level based on principles of conservation of momentum and energy which are described by the SaintVenant equations $[25,26,27]$.

The simulation was conducted in transient conditions for terms of dynamic wave. In analyses the models created during the ISOK project (IT System for Protection of the Country in Poland) were used, acquired from the Regional Water Management Authority in Wroclaw. Variables used in the models included only roughness parameters in floodplains. There were no boundary conditions verified for models nor were they for existing hydrotechnical objects. Thus, the acquired differences between variants A and B (described in following section) result solely from the vegetation impact.

\subsection{Roughness data}

The vegetation classification was conducted with use of ALS LIDAR data. For the purpose of model performance LIDAR data was obtained from CODGiK (Central Center for Geodetic and Cartographic Documentation). The mere classification of points cloud was outside the scope of this paper. The topic is discussed in numerous publications [2, 14, 18].

The LIDAR data were prepared in the scope of the ISOK project in 2012. They are executed in accordance with 1.2 standard published in 2008 by ASPRS (American Society for Photogrammetry and Remote Sensing) [28]. In the area of study, considering it is an urban terrain, the mean point density equals $12 \mathrm{pts} . / \mathrm{m}^{2}$, and the mean error of height fits within a range of $0.2 \mathrm{~m}$. The accuracy of points classification is not less than $95 \%$.

In the paper two computational variants were assumed for which simulations were processed. The first variant (A) encompassed an actual state, in which conditions of land use were taken into account with respect to LIDAR data. In the second variant (B) all of medium and high vegetal zones (bushes and trees) had roughness attributes of low grassland assigned. In order to assign the Manning coefficient $n$ to the classes of land use obtained from the cloud of points, the method of Bakula was adopted [29]. Coefficients taken for particular land use classes for A and B variants are presented in Table 2. 
The particular processing connected with the analysis of LIDAR data (import, merge, reclassify LAS and export to grid) were performed in SAGA (The System for Automated Geoscientific Analyses) software, which is an open source geographic information system (GIS) application, mainly licensed under the GNU General Public License [30]. Maps were created in ArcGIS for Desktop v.10.2 software [31].

Table 2. Cloud of points classification according to ASPRS with adopted values of Manning's coefficient for variants $A$ and $B$.

\begin{tabular}{|c|c|c|c|}
\hline \multicolumn{2}{|c|}{ Class } & Manning's $n$ variant A & Manning's $n$ variant B \\
\hline 0 & Unclassified & 0.05 & 0.05 \\
\hline 2 & Ground & 0.05 & 0.05 \\
\hline 3 & Low Vegetation & 0.07 & 0.07 \\
\hline 4 & Medium Vegetation & 0.10 & 0.07 \\
\hline 5 & High Vegetation & 0.14 & 0.07 \\
\hline 6 & Building & 1.00 & 1.00 \\
\hline 7 & Low Point (noise) & 0.05 & 0.05 \\
\hline 9 & Water & 0.001 & 0.001 \\
\hline
\end{tabular}

The result of each model is presented as a flood-prone zone. The aim is to compare the flood zones between the variant A with vegetation and the variant B with no high vegetal cover. In order to achieve this, the characteristics of flood zones are combined in respect of intensity, which includes area and flood depth. The abovementioned comparison was performed separately for two flow rates.

\section{Results and discussion}

Spatial parameters (bathymetry and resistance) were embedded in the model as a net with the resolution of $4 \mathrm{~m} \times 4 \mathrm{~m}$. According to that, the data acquired from LIDAR had to be fed into the aggregation function (resampling function in SAGA) in order to meet the resolution expected by the model. In Fig. 2 the roughness data incorporated into the model are presented for variants $\mathrm{A}$ and $\mathrm{B}$.

On the previously defined model the simulation was performed for water with the probability of occurrence $p=1 \%(100$-year water) and for water with the probability of occurrence $p=0.2 \%$ (500-year water). In Table 3 general hydraulic conditions acquired in models are defined. Fig. 3 shows maximal flood zones in the case of occurrence of 100-year water for both variants. Similar results are presented in Fig. 4 for 500 -year water.

In the case of greater flows (500-year water) flood zones are bigger, which is an obvious observation. For most of flows the greater impact of vegetation can be noticed, namely for both variants $\mathrm{A}$ and $\mathrm{B}$ the differences are bigger for 500-year water than for 100 -year water. The difference between maximal flood areas for both variants in the case of 100-year water equalled $816 \mathrm{~m}^{2}$, while for 500 -year water it was $1072 \mathrm{~m}^{2}$. For 100 -year water, the mean flood depth is in variant B $2.4 \mathrm{~cm}$ lower than in A, and for 500-year water that difference equals $4.8 \mathrm{~cm}$. In the case of maximal values of flood depth differences between variants for both probabilities of occurrence, 100-year and 500-year, equal $0.9 \mathrm{~cm}$ and $4.1 \mathrm{~cm}$ respectively. 

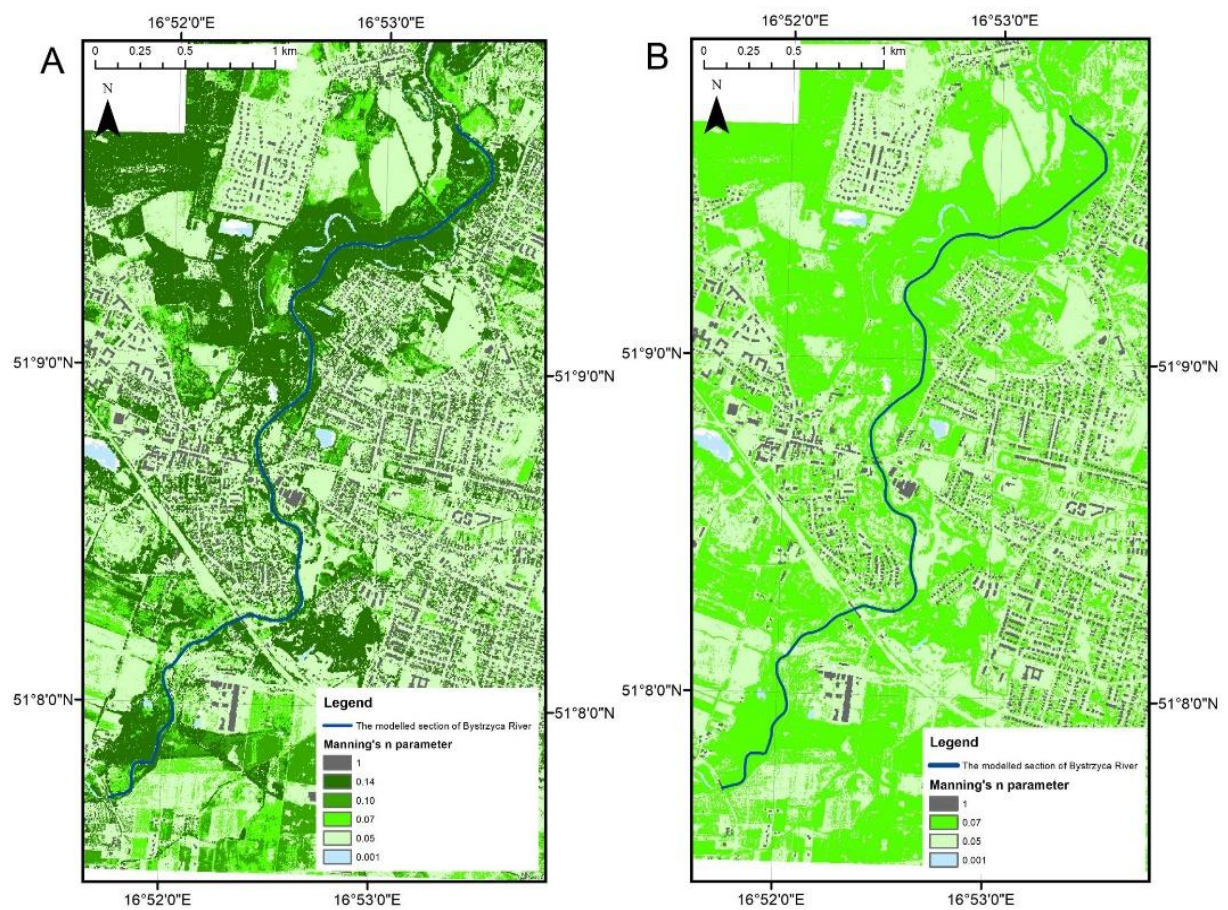

Fig. 2. Manning's $n$ parameter incorporated into the model for variants A (left) and B (right).

Table 3. Hydraulic conditions obtained in models for 100- and 500-year water.

\begin{tabular}{|c|c|c|c|c|c|c|}
\hline \multirow{2}{*}{ Parameter } & \multicolumn{3}{|c|}{100 -year water } & \multicolumn{3}{c|}{ 500-year water } \\
\cline { 2 - 3 } & \multicolumn{2}{|c|}{ Variant } & Difference & \multicolumn{2}{c|}{ Variant } & Difference \\
\cline { 2 - 3 } \cline { 5 - 6 } & $\mathrm{A}$ & $\mathrm{B}$ & A and B & $\mathrm{A}$ & $\mathrm{B}$ & A and B \\
\hline Max depth water $[\mathrm{m}]$ & 5.329 & 5.320 & 0.009 & 5.785 & 5.744 & 0.041 \\
\hline Mean depth water $[\mathrm{m}]$ & 1.209 & 1.185 & 0.024 & 1.322 & 1.274 & 0.048 \\
\hline Max water area $\left[\mathrm{m}^{2}\right]$ & 117616 & 116800 & 816 & 217104 & 216032 & 1072 \\
\hline
\end{tabular}
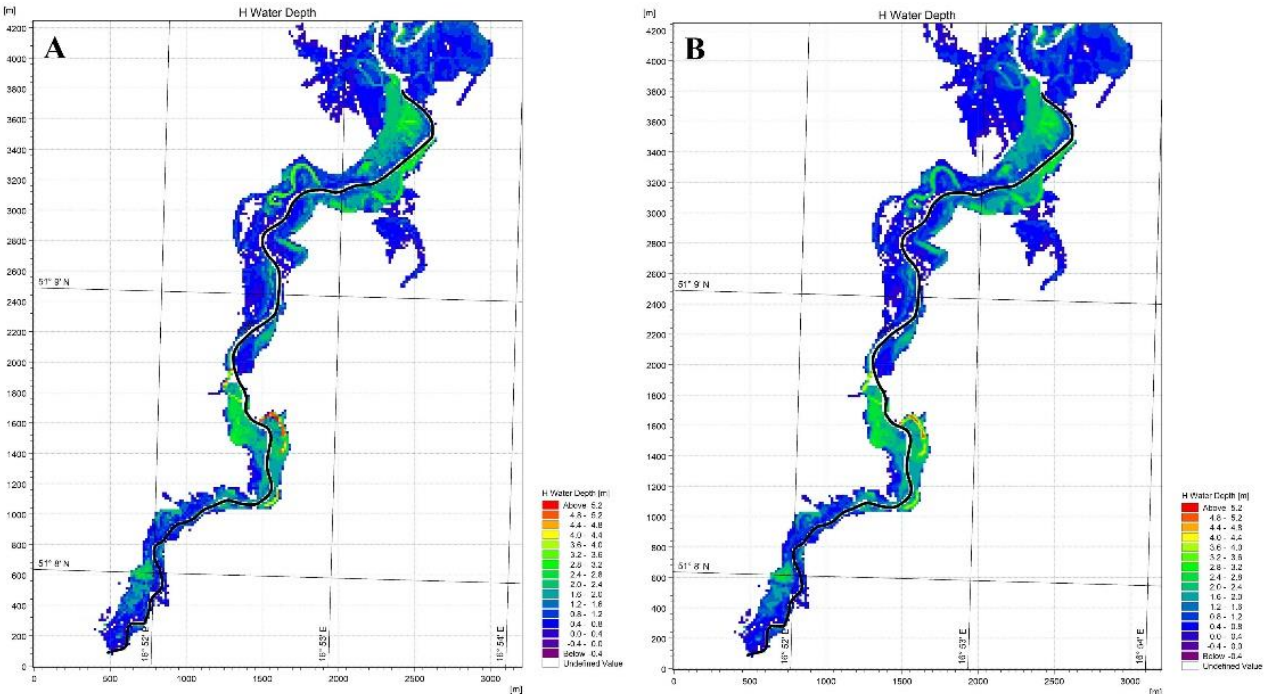

Fig. 3. Maximal flood zone for 100 -year water in variant A (left) and B (right). 

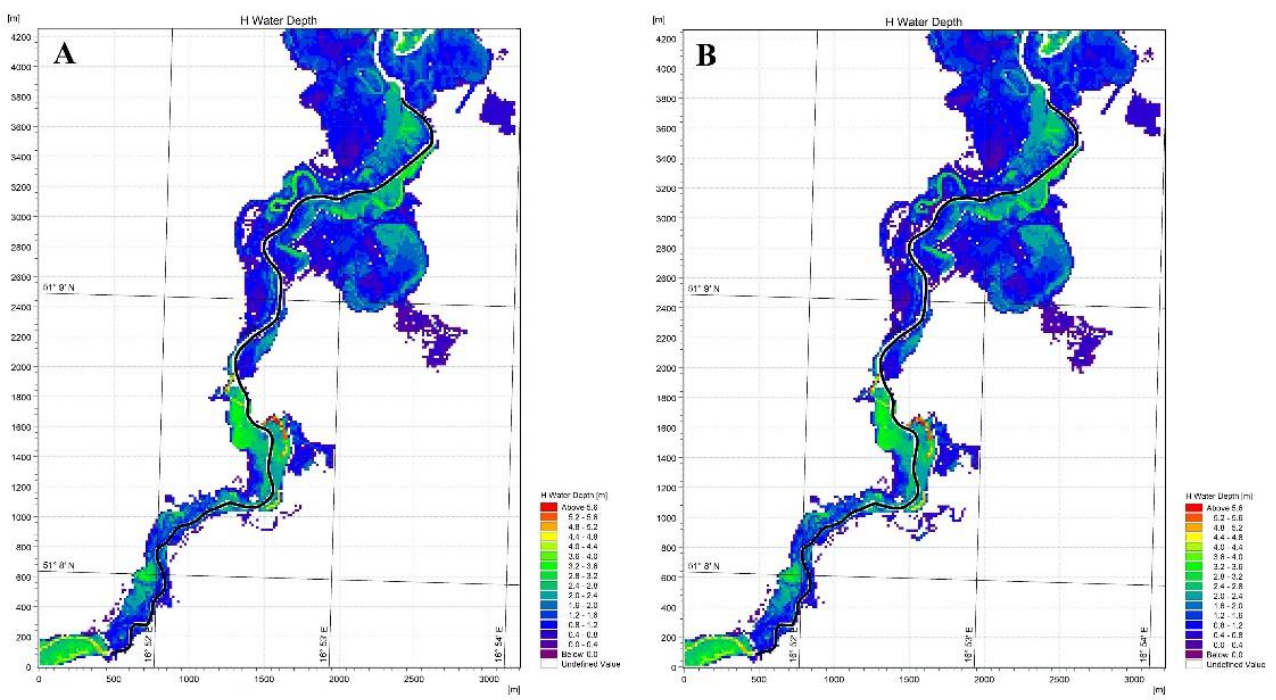

Fig. 4. Maximal flood zone for 500-year water in variant A (left) and B (right).

\section{Conclusions}

In the paper, an attempt was made to verify the notion of significant impact of vegetation on water damming during the transition of the flood wave. Acquired results do not indicate such a big impact on water depth that would be derived with empirical computations ca. $0.5 \mathrm{~m}$ [19]. However, the authors cannot fully disagree with the thesis stating the significant impact of vegetation. Tyminski in his research [19] used extreme water from the 1997 flood with the probability of occurrence $p=0.02 \%$ as boundary conditions. The impact of vegetation stated in the paper, which increases together with the level of flow, can further indicate that the greater the water, the bigger the impact of vegetation. Nevertheless, this assumption cannot be accepted with certainty while based on two observations included in this paper, and there is a need for further investigation with use of more observations. The results can also be influenced by local conditions, which the authors could not eliminate. A validation conducted on other river segments could increase the fairness of the research. What is significant is that the paper proves the use of LIDAR data in the determination of bathymetry and roughness is possible and the use of this data in 2D modelling allows to evaluate the impact of vegetation on the transition of flood wave.

We thank the anonymous reviewer for their careful reading of our manuscript and their many insightful comments. The study used software MIKE Powered by the DHI Software license student. The authors want to thank DHI for making the MIKE FLOOD software available for the PhD thesis. The authors also want to thank the Regional Board of Water Management in Wroclaw for providing hydraulic models from the ISOK project. In this study we used LIDAR data from CODGiK (Central Center for Geodetic and Cartographic Documentation) under licence No. DIO.7211.197.2016_PL_N.

\section{References}

1. M.G. Macklin, J. Lewin, J. Quat. Sci. 18, 101 (2003)

2. G. Forzieri, F. Castelli, F. Preti, Int. J. Remote Sens. 33/2, 630 (2012) 
3. G. Blöschl, L. Gaál, J. Hall, A. Kiss, J. Komma, T. Nester, J. Parajka, R.A.P. Perdigão, L. Plavcová, M. Rogger, J.L. Salinas, A. Viglione, WIREs Water 2, 329 (2015)

4. Z.W. Kundzewicz, Changes in Flood Risk in Europe (CRC Press, Wallingford, 2012)

5. J. Teng, A.J. Jakeman, J. Vaze, B.F.W. Croke, D. Dutta, S. Kim, Environ. Modell. Softw. 90, 201 (2017)

6. G. Mandlburger, C. Hauer, B. Höfle, H. Habersack, N. Pfeifer, Hydrol. Earth Syst. Sci. 13, 1453 (2009)

7. H. Dorn, M. Vetter, B. Höfle, Remote Sens. 6, 1739 (2014)

8. N. Walczak, M. Hammerling, M. Spychała, J. Niec, J. Ecol. Eng 16/5, 160 (2015)

9. V.T. Chow, Open-Channel Hydraulics (McGraw-Hill, Tokyo, 1959)

10. M. Straatsma, M. J. Baptist, Remote Sens. Environ. 112, 1062 (2008)

11. G.J Arcement, V.R Schneider, Guide for Selecting Manning's Roughness Coefficients for Natural Channels and Flood Plains (U.S. Geological Survey Water, Denver, 1989)

12. N. Kouwen, J. Irrig. Drain Eng. 118, 559 (1992)

13. I. Zahidi, Y. Badronnisa, M. Cope, Research in Civil and Environ. Eng. 2, 1 (2014)

14. M. Straatsma, F. Huthoff, Phys. Chem. Earth 36, 324 (2011)

15. G. Forzieri, L. Guarnieri, E.R. Vivoni, F. Castelli, F. Preti, River Res. Appl 27, 826 (2011)

16. G. Forzieri, M. Degetto, M. Righetti, F. Castelli, F. Preti, J. Hydrol 407, 41 (2011)

17. S. Medeiros, S.C. Hagen, J.F. Weishampel, J Hydrol 452-453, 139 (2012)

18. P. Tymkow, Application of photogrammetric and remote sensing methods for identification of resistance coefficients of high water flow in river valleys (Wydawnictwo Uniwersytetu Przyrodniczego we Wroclawiu, Wroclaw, 2009)

19. T. Tyminski, Zeszyty Naukowe Akademii Rolniczej we Wrocławiu. Monografie. 36, 49 (2004)

20. B.C. Yen, J. Hydraul. Eng. 128, 20 (2002)

21. J. Järvelä, Flow resistance in environmental channels: Focus on vegetation (Helsinki University of Technology Water Resources Publications, Espoo, 2004)

22. D.C.M. Augustijn, F. Huthoff, E.H. van Velzen, Proceedings of River Flow $2008-4^{\text {th }}$ International Conference on Fluvial Hydraulics, Izmir, Turkey, 343 (Ankara Kubaba Congress Department and Travel Services, Ankara, 2008)

23. W.L. Cowan, Agricultural Engineering 37, 473 (1956)

24. H. Nepf, J. Hydraul. Res. 50, 262 (2012)

25. DHI, MIKE FLOOD. 1D-2D Modelling. User Manual. (DHI, Hørsholm, 2017)

26. DHI, MIKE 21 Flow Model and MIKE 21 Flood Screening Tool. Hydrodynamic Module. Scientific Documentation (DHI, Hørsholm, 2017)

27. M. Gharbi, A. Soualmia, D. Dartus, L. Masbernat, J. Mater. Environ. Sci. 7, 3017 (2016)

28. ASPRS, LAS Specification Version 1.2 (ASPRS, Bethesda, 2008)

29. K. Bakula, Archiwum Fotogrametrii, Kartografii i Teledetekcji 26, 23 (2014)

30. O. Conrad, B. Bechtel, M. Bock, H. Dietrich, E. Fischer, L. Gerlitz, J. Wehberg, V. Wichmann, J. Boehner, Geosci. Model Dev. 8, 1991 (2015)

31. M. Schmidts, Esri ArcGIS Desktop Associate Certification Study Guide (ESRI Press, Redlands, 2013) 